\title{
VII Encuentro de Cátedras de Pedagogía de Universidades Nacionales
}

\author{
Natalia Fattore \\ (Escuela de Ciencias de la Educación) \\ (Universidad Nacional de Rosario-Argentina)
}

Durante los días 2, 3 y 4 de septiembre de 2009, se llevó a cabo en la Facultad de Humanidades y Artes de la UNR el "VII Encuentro de Cátedras de Pedagogía de Universidades Nacionales: La pedagogía en el pensamiento contemporáneo: debates, encuentros y desafíos".

Estos encuentros se realizan cada dos años, y la Universidad anfitriona y la cátedra organizadora fijan una agenda de discusiones que tienen relación con la trayectoria que la casa de altos estudios posee.

En esta oportunidad, la reunión tuvo como objetivo principal abrir la discusión, propiciar el intercambio de ideas y de reflexiones -entre todos los docentes de las Universidades públicas e institutos, que enseñamos pedagogía o disciplinas afines- acerca de los alcances de la Pedagogía, y el diálogo que la misma como saber, establece con el resto de las disciplinas de las Ciencias Sociales.

Así, las diferentes mesas de trabajo hicieron foco en los debates y tensiones que la Pedagogía afronta, y desde donde participa en las actuales discusiones contemporáneas en el campo de las ciencias humanas y sociales.

Desde problemas tales como las identidades, la cultura, el conocimiento y el poder, la política, la formación de las subjetividades, la estética; la intención fue abordar la configuración del campo de la educación en un presente que se ofrece complejo y problemático. Presente que requiere miradas donde la pedagogía se abra al diálogo con otras disciplinas.

Estos encuentros tienen siempre una modalidad de trabajo sumamente especial, que a los profesores de las distintas universidades nos resulta muy rica: son encuentros horizontales, en el sentido de que todos los que trabajan, sean profesores titulares, adjuntos, JTP, de cualquier Universidad o Instituto tienen la misma voz.

En este sentido es que lo llamamos "encuentro", ya que los trabajos son organizados en mesas de discusión, en las cuales se pueden encontrar desde 
el titular de una facultad de una cátedra muy reconocida con mucha trayectoria, con alguien que recién está empezando la carrera docente.

Las conferencias de inicio y de cierre del encuentro estuvieron a cargo de los Profesores Marcelo Caruso y Estanislao Antelo.

La actividad tuvo este año la característica de traer al recuerdo la labor de la Profesora Leonor Bella de Paz. Así, en la apertura del VII Encuentro se llevó a cabo un pequeño homenaje a la docente que ha estado al frente de la cátedra durante muchos años.

Hubo también espacios específicos donde se presentaron experiencias de cátedra y propuestas innovadoras en la enseñanza de la disciplina, así como alternativas de extensión que desde este campo se ofrecen en el espacio universitario.

Los miembros de la cátedra y la Escuela de Ciencias de la Educación trabajamos arduamente para llevar adelante el encuentro, del que participaron más de doscientos docentes y alumnos de Universidades Nacionales de todo el país.

Las Jornadas funcionaron como un espacio de debate muy fuerte, plural ideológicamente, plural en posiciones teóricas, ya que se pudieron escuchar enfoques muy distintos de abordar la materia y sus problemas fundantes.

Creemos que el Encuentro sirvió principalmente para seguir afianzando un espacio colectivo de debate acerca del campo disciplinar y epistemológico de la Pedagogía. 